\title{
Weather-Based Models for Assessing the Risk of Sclerotinia sclerotiorum Apothecial Presence in Soybean (Glycine max) Fields
}

\begin{abstract}
Jaime F. Willbur, Department of Plant Pathology, University of Wisconsin-Madison, Madison; Mamadou L. Fall, Saint-Jean-sur-Richelieu Research and Development Centre, Agriculture and Agri-Food Canada, Saint-Jean-sur-Richelieu, QC, Canada; Christopher Bloomingdale, Department of Agronomy, University of Wisconsin-Madison; Adam M. Byrne, Department of Plant, Soil and Microbial Sciences, Michigan State University, East Lansing; Scott A. Chapman, Department of Plant Pathology, University of Wisconsin-Madison; Scott A. Isard, Department of Plant Pathology and Environmental Microbiology, and Department of Meteorology, Pennsylvania State University, University Park; Roger D. Magarey, NSF Center for Integrated Pest Management, North Carolina State University, Raleigh; Megan M. McCaghey and Brian D. Mueller, Department of Plant Pathology, University of Wisconsin-Madison; Joseph M. Russo and Jay Schlegel, ZedX, Incorporated, Bellefonte, PA; Martin I. Chilvers, Department of Plant, Soil and Microbial Sciences, Michigan State University; Daren S. Mueller, Department of Plant Pathology and Microbiology, Iowa State University, Ames; and Mehdi Kabbage and Damon L. Smith, ${ }^{\dagger}$ Department of Plant Pathology, University of Wisconsin-Madison
\end{abstract}

\begin{abstract}
Sclerotinia stem rot (SSR) epidemics in soybean, caused by Sclerotinia sclerotiorum, are currently responsible for annual yield reductions in the United States of up to 1 million metric tons. In-season disease management is largely dependent on chemical control but its efficiency and cost-effectiveness depends on both the chemistry used and the risk of apothecia formation, germination, and further dispersal of ascospores during susceptible soybean growth stages. Hence, accurate prediction of the S. sclerotiorum apothecial risk during the soybean flowering period could enable farmers to improve in-season SSR management. From 2014 to 2016, apothecial presence or absence was monitored in three irrigated ( $n=1,505$ plot-level observations) and six nonirrigated $(n=2,361$ plot-level observations) field trials located in Iowa $(n=156)$, Michigan $(n=1,400)$, and Wisconsin $(n=2,310)$, for a total of 3,866 plot-level observations. Hourly air temperature, relative humidity, dew point, wind speed, leaf wetness, and rainfall were also monitored continuously, throughout the

season, at each location using high-resolution gridded weather data. Logistic regression models were developed for irrigated and nonirrigated conditions using apothecial presence as a binary response variable. Agronomic variables (row width) and weather-related variables (defined as 30-day moving averages, prior to apothecial presence) were tested for their predictive ability. In irrigated soybean fields, apothecial presence was best explained by row width $(r=-0.41, P<0.0001), 30$-day moving averages of daily maximum air temperature $(r=0.27, P<0.0001)$, and daily maximum relative humidity $(r=0.16, P<0.05)$. In nonirrigated fields, apothecial presence was best explained by using moving averages of daily maximum air temperature $(r=-0.30, P<0.0001)$ and wind speed $(r=$ $-0.27, P<0.0001$ ). These models correctly predicted (overall accuracy of 67 to $70 \%$ ) apothecial presence during the soybean flowering period for four independent datasets $(n=1,102$ plot-level observations or 30 daily mean observations).
\end{abstract}

Sclerotinia stem rot (SSR), also known as white mold, is caused by Sclerotinia sclerotiorum and consistently ranks in the top 10 diseases plaguing soybean crops worldwide (Allen et al. 2017; Lehner et al. 2017; Wrather et al. 2010). In 2014, SSR was responsible for a yield reduction in soybean-growing regions of the United States of 1.1 million metric tons, which cost farmers approximately $\$ 511$ million according to market prices (Allen et al. 2017; Bradley et al. 2016; USDA-NASS 2017). $S$. sclerotiorum is infamously characterized by its broad host range (>400 host species) and longevity in the soil (as soilborne sclerotia), and the subsequently devastating crop losses (Boland and Hall 1994; Peltier et al. 2012). Thus, SSR management is justifiably ranked high in significance and concern in the north-central region of the United States.

Ascospores produced from $S$. sclerotiorum apothecia are the primary source of inoculum for infection by this fungus in soybean (Abawi and Grogan 1975; Grau and Hartman 2015; Peltier et al. 2012; Saharan and Mehta 2008). Ascospores are wind dispersed onto senescing flowers, which provide a source of nutrients for successful mycelial colonization (Grau and Hartman 2015; Grau et al. 1982; Saharan and Mehta 2008). Despite the variety of strategies used in SSR management (Peltier et al. 2012), effective in-season control depends on chemical applications, which are primarily targeted at protecting flowers from

${ }^{\dagger}$ Corresponding author: D. L. Smith, E-mail: damon.smith@wisc.edu

*The $\boldsymbol{e}$-Xtra logo stands for "electronic extra" and indicates that one supplementary figure is published online.

Accepted for publication 26 August 2017.

C) 2018 The American Phytopathological Society ascospore infection. Because environmental conditions conducive for apothecial germination often coincide with soybean flowering, or between the R1 (first bloom) to R3 (first pod forming) growth stages (Fehr et al. 1971), the risk of disease onset should be assessed and addressed during this period. It would be beneficial to farmers if they were informed of (i) risk of apothecial formation during the flowering period and (ii) if and when fungicides should be applied for economic and optimal control during the flowering period.

Soybean flowering, apothecial germination, and weather conditions conducive for infection must occur simultaneously for SSR development. Due to this complex array of factors, and the difficulty for farmers to assess these factors efficiently during the season, fungicide applications may be unnecessary or ineffective as a result of unsuitable timing (Mueller et al. 2004). Accordingly, the development of a model to predict the risk of disease development in soybean is key to effectively timing fungicide applications for SSR control. Disease forecasting models have been developed and tested for predicting diseases caused by Sclerotinia spp. in other crops such as peanut (Smith et al. 2007), carrot (Foster et al. 2011), lettuce (Clarkson et al. 2007, 2014), dry bean (Harikrishnan and del Río 2008), and canola (Twengström et al. 1998). In lettuce, under controlled environment conditions, ascospore density ( $>87$ spores $\left.\mathrm{cm}^{-2}\right)$, temperature $\left(21.7^{\circ} \mathrm{C}\right.$ optimal), and relative humidity (RH) (80 to 100\%) were all important to predict S. sclerotiorum infection (Clarkson et al. 2014). In another study, 30 to 50 days at temperatures of 18 to $20^{\circ} \mathrm{C}$ was found to be optimal for apothecial germination, dependent on the $S$. sclerotiorum isolate (Clarkson et al. 2007). Collectively, these findings suggest that temperature and moisture over a period of 30 to 50 days prior to sclerotial germination influence apothecial development.

Models incorporating soil temperature (maximum of $24^{\circ} \mathrm{C}$ ) and moisture $(\geq 20 \mathrm{kPa})$ were able to predict development of apothecia 
and ascospores of Sclerotinia rot in carrot (Foster et al. 2011). In a 2year field evaluation study, the model reduced the total number of fungicide applications compared with a typical calendar-spray regime and achieved an equivalent level of control (Foster et al. 2011). Soil parameters are often difficult to simulate and acquire for site-specific predictions unless an on-site meteorological-grade weather station is used. Simulated, model-derived weather data, however, are readily available for most air temperature and moisture variables. In the United States, simulated downscaled weather data are created by numerical weather models that use weather station data and remote sensing to generate weather data at grid resolutions of $5 \mathrm{~km}$ (Benjamin et al. 2007). Models generated using these publicly available data allow the disease prediction models to be more widely accessible to farmers and functional in virtually any growing location (Magarey et al. 2001).

Studies in China have investigated correlations between the numbers of apothecia present during the soybean blossom stage and disease index with yield loss measurements (Pan et al. 2001; Saharan and Mehta 2008). Both number of apothecia and disease index were negatively correlated with yield, and an action threshold for implementing chemical control was established at 3 to 4 apothecia per $9.75 \mathrm{~m}^{2}$ (Pan et al. 2001). However, apothecial size (approximately 0.5 to $10 \mathrm{~mm}$ in diameter) (Grau and Hartman 2015; Kohn 1979) and aggregated distribution within a field (Boland and Hall 1988b) make this model difficult to implement for soybean farmers. A study conducted in the north-central region of the United States used logistic regression to model the prevalence (proportion of diseased fields within a large production region) of soybean SSR (Mila et al. 2004). Using total precipitation and air temperature in either April or July combined with regional tillage practices, disease prevalence was modeled at a regional level. This model, however, although useful at the regional level, was not accurate at the field level (Mila et al. 2004). Therefore, farmers in the north-central region of the United States would benefit from an accurate, site-specific model to predict the risk of SSR at the soybean field level where management decisions are applied.

Historically, S. sclerotiorum apothecia and SSR incidence were both spatially aggregated and correlated within sectors of white bean and soybean fields (Boland and Hall 1988a,b). More recently, the spatial distribution of SSR has been correlated with apothecia in both canola (Qandah and del Rio Mendoza 2012) and soybean (Wegulo et al. 2000). In both studies, disease incidence (DI) decreased as distance from apothecial inoculum sources increased. Furthermore, the majority of ascospores were deposited near apothecia (Wegulo et al. 2000), which supports the relationship between apothecia and disease. Therefore, apothecial presence is a promising candidate to use for SSR risk assessment in soybean fields.

The ultimate goal of this research is to develop and test the usefulness of a risk prediction model that can be further integrated into a decision-support system to help farmers make economic and environmentally friendly decisions related to fungicide use and timing. To address this goal, empirically derived logistic regression models were developed using downscaled gridded weather data to predict the risk of $S$. sclerotiorum apothecial presence in soybean fields.

\section{Materials and Methods}

Study area and experimental conditions. Wisconsin. In 2014, 2015, and 2016, apothecial populations were intensively monitored in small-plot field trials established at University of Wisconsin-Madison Agricultural Research Stations (Table 1), in fields with a known history of S. sclerotiorum infestation. Trials used in this study were planted in locations with soil types representative of the state and using cultivars with typical flowering periods for the region (Table 1). In 2014 and 2015, trials located in West Madison, WI were planted on 30 and 13 May, respectively. Small four-row plots, $6.1 \mathrm{~m}$ long by $3.0 \mathrm{~m}$ wide, were planted at a $0.76-\mathrm{m}$ row spacing and at a density of 375,000 seeds/ha in 2014 or 350,000 seeds/ha in 2015.

In 2016, small plots were planted on 18 May at 350,000 seeds/ha with a $0.76-\mathrm{m}$ row spacing in trials located in Arlington, WI. An additional trial subjected to overhead irrigation was planted on 17 May in Hancock, WI. This trial was planted at 350,000 seeds/ha with a
0.76- $\mathrm{m}$ row spacing. Plots were generally irrigated every 2 to 5 days at a rate of 1.9 to $3.2 \mathrm{~cm} / \mathrm{ha}$.

Field trials used for apothecial monitoring were established as cultivar or fungicide evaluations; treatments were replicated five times and arranged in a randomized complete block design. Trials were surrounded by at least $3.0 \mathrm{~m}$ of buffer soybean plants, $1.5-\mathrm{m}$ alleys were cleared between each block, and data were collected in the center two rows of each plot. Inoculum in field sites was augmented by planting sunflower crops inoculated with three $S$. sclerotiorum isolates (collected in Wisconsin). The sunflower crops were planted and inoculated 1 or 2 years prior to the soybean crop being planted. Shallow-depth field cultivation was used to uniformly incorporate sclerotia into the upper soil profile after sunflower harvest. SSR nursery infestations were maintained with yearly rotations of soybean and sunflower and repeated sunflower inoculations.

Michigan. Trials used in this study were conducted with cultivars and soil types representative of the state (Table 1). In 2015, apothecial observations were collected from four field trials planted on 21 May at the Michigan State University Research Center in Montcalm, MI. All Montcalm trials were overhead irrigated to supplement local rainfall.

In 2015, trials were irrigated approximately once a week between 6 July and 12 August with water at 5.4 to $6.4 \mathrm{~cm} / \mathrm{ha}$. One trial was planted at $0.76-\mathrm{m}$ row spacing and contained 10 plots, which were $12.2 \mathrm{~m}$ long by $6.1 \mathrm{~m}$ wide. A second trial was planted at $0.36-\mathrm{m}$ row spacing containing nine plots, which were $12.2 \mathrm{~m}$ long by $6.1 \mathrm{~m}$ wide. The two other trials were planted at either a 0.76 - or $0.36-\mathrm{m}$ row spacing, with each containing eight four- or six-row plots, which were $12.2 \mathrm{~m}$ long and $3.0 \mathrm{~m}$ wide. These trials also doubled as replicated fungicide evaluations. Fungicide treatments were replicated four times and arranged in a randomized complete block design.

In 2016, apothecial counts were collected from two nonfungicidetreated, irrigated trials. Trials were planted 17 May at either a 0.76- or $0.38-\mathrm{m}$ row spacing. Small, four- or six-row plots, which were $6.1 \mathrm{~m}$ long by $3.0 \mathrm{~m}$ wide, were planted at a target density of 400,000 seeds/ha. Plots were irrigated approximately once per week, similarly to 2015 .

In 2016, additional apothecial observations were collected in an on-farm trial located in Ionia, MI; this trial was nonirrigated, not treated with fungicide, and planted at a $0.38-\mathrm{m}$ row spacing. The field was divided into five square plots of 21.0 by $21.0 \mathrm{~m}$ each.

Iowa. In 2016, apothecial presence data were collected from two nonirrigated trials located in Manilla and Nashua, IA (Table 1). Manilla and Nashua trials were planted on 8 May at a row spacing of $0.76 \mathrm{~m}$ and at seeding rates of 375,000 and 475,000 seeds/ha, respectively. In Manilla, apothecia were monitored in a fungicide trial with 24 replicated treatments. In Nashua, the trial evaluated six fungicide treatments. Treatments in both trials were arranged in a randomized complete block design with four replicates. Small, four-row plots were $6.1 \mathrm{~m}$ long by $3.0 \mathrm{~m}$ wide and blocks were separated by $1.5-\mathrm{m}$ alleys. The trials used for this research were conducted with cultivars and soil types representative of the state (Table 1).

Data collection and response variables. Apothecia counts. Wisconsin. Scouting for apothecia began prior to the R1 growth stage (first flower) and typically continued twice weekly until either complete apothecial senescence or until plants reached the $\mathrm{R} 7$ growth stage (beginning maturity). At each observation day, three areas of 0.76 by $0.76 \mathrm{~m}$ each were examined between the center two rows (yield rows) in each plot. Squares were arbitrarily placed at three locations throughout the $6.1-\mathrm{m}$ length of the plot and apothecial numbers were recorded at each stop. In 2014, scouting was conducted for 7 weeks from 52 to 102 days after seeding (DAS), between the R3 (beginning pod) and R7 growth stages $(n=520)$. In 2015, scouting was conducted for 8 weeks from 48 to 105 DAS, between the V4 (fourth trifoliate) and R6 (full pod) growth stages $(n=400)$. In 2016, the trial in Arlington, WI was scouted for 8 weeks from 37 to $97 \mathrm{DAS}$, or from the V5 (fifth trifoliate) to R5 (beginning seed) growth stages $(n=1,125)$. At the Hancock trial in 2016, scouting was conducted three times at 44, 57, and 78 DAS, which were at the V6 (sixth trifoliate), R2 (full flowering), and R5 growth stages $(n=225)$.

Michigan. In 2015, apothecial counts were taken twice weekly in eight squares ( 0.76 by $0.76 \mathrm{~m}$ each) placed arbitrarily throughout each 
plot of the four total trials, and daily totals were recorded per plot. In the two nontreated trials, 10 plots were scouted in the $0.76-\mathrm{m}$ row spacing and nine plots in the 0.36-m spacing trial. In the two fungicide trials, all eight plots were scouted for every observation day. Scouting was conducted in every trial for 12 weeks from 36 to 125 DAS, which began prior to the R1 growth stage and continued through the R6 growth stage $(n=720)$.

In 2016 in Montcalm, four plots per trial were scouted twice weekly for 10 weeks from 28 to 100 DAS $(n=560)$. Apothecial counts were taken in four squares ( 0.76 by $0.76 \mathrm{~m}$ each) placed arbitrarily throughout the plot and totals were recorded for each stop. Daily apothecial means for this study were generated for each day per trial, as previously described.

In 2016 in Ionia, apothecial counts were collected in four squares ( 0.76 by $0.76 \mathrm{~m}$ each) arbitrarily placed throughout the square plots and totals were recorded for each stop. Counts were collected on 6 days over the course of 4 weeks beginning just prior to R 1 and continuing until the $\mathrm{R} 4$ (full pod) growth stage $(n=120)$.

Iowa. Apothecial counts were taken in three squares $(0.76$ by $0.76 \mathrm{~m}$ each) placed arbitrarily throughout the center two rows of each nontreated plot of each trial. The total apothecia in each square were recorded per plot. Both Manilla and Nashua locations were scouted once a week for five to six weeks, including the approximate two-week flowering period, from around 53 to 96 DAS $(n=156)$.

Ascospore trapping. Wisconsin. Ascospore presence was monitored in Wisconsin trials from 2014 to 2016. Spores were detected using bromophenol blue semiselective media (SSM) in Petri plates (Foster et al. 2011; Steadman et al. 1994). These "spore-trapping" plates consisted of standard 90-mm Petri plates containing potato dextrose agar (PDA) amended with $75 \%$ pentachloronitrobenzene at $25 \mathrm{mg} \mathrm{liter}^{-1}$, penicillin $\mathrm{G}$ (potassium salt) at $150 \mathrm{mg} \mathrm{liter}^{-1}$, streptomycin sulfate at $150 \mathrm{mg} \mathrm{liter}^{-1}$, and bromophenol blue indicator at $50 \mathrm{mg} \mathrm{liter}{ }^{-1}$. As in the Foster et al. (2011) study, SSM plates were placed beneath the soybean canopy at a $45^{\circ}$ angle, facing upwind, and were exposed between 09:00 and 14:00 h. In Wisconsin, plates were exposed beneath the soybean canopy for three consecutive hours. Plates were incubated at room temperature $\left(21\right.$ to $\left.24^{\circ} \mathrm{C}\right)$ for 2 to 3 days and then evaluated for the presence of S. sclerotiorum CFU. CFU were distinguishable by the characteristic yellow halo surrounding the small, circular, translucent white colonies. Colonies were best visualized using backlighting, or a dissecting microscope in the case of heavily infested plates. Discrete CFU were considered to result from a single ascospore, and S. sclerotiorum detection was confirmed by formation of subsequent characteristic sclerotia after subculturing representative colonies.

In Wisconsin trials, seven or eight SSM plates were placed evenly across two perpendicular transects, oriented north to south and east to west. Spores were monitored twice a week in the trial that was also monitored for apothecial presence. To avoid disturbance of apothecia, plates were placed in nonyield rows during the time of exposure. In 2014, ascospore presence was monitored from 62 to 80 DAS, between the R4 and R5 growth stages. In 2015 and 2016, spores were monitored for 6 to 7 weeks from the V4/5 to R5 growth stages.

Michigan. Ascospore presence was also monitored in Michigan trials from 2015 to 2016. The spore plates were used as previously described; however, in Michigan, spore plates were exposed between 1 and $3 \mathrm{~h}$. In 2015, ascospores were monitored in eight plots of the nontreated trial planted at a $0.76-\mathrm{m}$ row spacing. One plate was placed in each of the eight plots and spores were monitored from 55 to 118 DAS. In 2016, ascospore observations were collected from eight spore plates placed in nontreated trials, four in the $0.76-\mathrm{m}$ row spacing trial and four placed in the $0.38-\mathrm{m}$ spacing trial. Spores were monitored from 51 to 70 DAS.

Descriptive and correlation analysis. All statistical analyses throughout this study were conducted in SAS (v. 9.4; SAS Institute). Daily apothecial means for this study were estimated for each treatment using a mixed-model analysis of variance in PROC GLIMMIX; treatment was used as the fixed effect and replicate was considered a random effect. A binary irrigation variable was generated based on the absence (0) or presence (1) of overhead irrigation during the season. A binary fungicide variable was generated based on the absence $(0)$ or presence (1) of a fungicide application during the season.

Two and three years of apothecial observations from Michigan and Wisconsin $(n=557)$, respectively, were used with corresponding ascospore observations $(n=399)$ in correlation analyses. Ascospore numbers were correlated with apothecial numbers taken from the same trials on the same days of plate exposure. Daily means of apothecial counts and corresponding ascospore CFU were estimated using a mixed-model analysis of variance in PROC GLIMMIX; the LSMEANS estimates for each day were used in correlation analyses.

Table 1. Years and locations of apothecial data collection with corresponding GPS coordinates (used to obtain high-resolution, site-specific downscaled gridded real-time mesoscale analysis weather data), irrigation specification (IR), row spacing designation (Row), number of observations $(N)$, cultivar information, and soil properties

\begin{tabular}{|c|c|c|c|c|c|c|c|c|c|c|c|c|c|}
\hline \multirow[b]{2}{*}{ Year, state } & \multirow[b]{2}{*}{ Location } & \multirow[b]{2}{*}{ GPS coordinates } & \multirow[b]{2}{*}{ IR } & \multirow[b]{2}{*}{ Row (m) } & \multirow[b]{2}{*}{$N$} & \multirow[b]{2}{*}{ Cultivar } & \multirow[b]{2}{*}{$\mathbf{F P}^{\mathbf{a}}$} & \multirow[b]{2}{*}{ Soil type ${ }^{b}$} & \multirow[b]{2}{*}{ Slope (\%) } & \multicolumn{4}{|c|}{ Content (\%) } \\
\hline & & & & & & & & & & $\overline{\text { OM}^{\mathrm{c}}}$ & Clay & Sand & $\overline{\text { Silt }}$ \\
\hline \multicolumn{14}{|l|}{2014} \\
\hline Wisconsin & West Madison & $43.0637,-89.5335$ & - & 0.76 & 560 & $\begin{array}{c}\text { BSR-101 (S); } \\
91-145(\mathrm{R})\end{array}$ & 11 & Kegonsa silt loam & $2-6$ & 1.0 & 13.4 & 50.2 & 36.5 \\
\hline \multicolumn{14}{|l|}{2015} \\
\hline Michigan & Montcalm & $43.3525,-85.1788$ & + & $0.76,0.36$ & 720 & AG2535 & 14 & $\begin{array}{l}\text { Tekenink-Elmdale } \\
\text { loamy sands }\end{array}$ & $2-6$ & 0.3 & 9.9 & 69.4 & 20.7 \\
\hline Wisconsin & West Madison & $43.0692,-89.5424$ & - & 0.76 & 400 & AG2031 & 20 & $\begin{array}{l}\text { Plano silt loam, } \\
\text { gravelly } \\
\text { substratum }\end{array}$ & $0-2$ & 1.4 & 20.9 & 33.3 & 45.8 \\
\hline \multicolumn{14}{|l|}{2016} \\
\hline Iowa & Manilla & $41.8495,-95.1751$ & - & 0.76 & 72 & P25T51R & 14 & $\begin{array}{l}\text { Judson-Ackmore- } \\
\text { Colo, overwash } \\
\text { complex }\end{array}$ & $1-5$ & 2.1 & 29.2 & 5.5 & 65.3 \\
\hline Iowa & Nashua & $42.9382,-92.5696$ & - & 0.76 & 84 & P24T93R & 14 & $\begin{array}{l}\text { Clyde silty clay } \\
\text { loam }\end{array}$ & $0-3$ & 2.2 & 25.0 & 32.4 & 42.6 \\
\hline Michigan & Ionia & $43.0222,-84.9974$ & - & 0.38 & 120 & P92Y91R & 14 & Marlette loam & $0-6$ & 0.5 & 21.6 & 44.3 & 34.1 \\
\hline Michigan & Montcalm & $43.3525,-85.1788$ & + & $0.76,0.38$ & 560 & AG2535 & 17 & $\begin{array}{l}\text { Tekenink-Elmdale } \\
\text { loamy sands }\end{array}$ & $2-6$ & 0.3 & 9.9 & 69.4 & 20.7 \\
\hline Wisconsin & Arlington & $43.3191,-89.3312$ & - & 0.76 & 1,125 & AG2031 & 13 & Joy silt loam & $0-4$ & 1.3 & 20.5 & 10.1 & 69.4 \\
\hline Wisconsin & Hancock & $44.1132,-89.5463$ & + & 0.76 & 225 & AG2031 & 15 & Plainfield sand & $0-2$ & 0.3 & 2.4 & 94.9 & 2.7 \\
\hline
\end{tabular}

\footnotetext{
${ }^{a}$ Approximate flowering period (FP) in days.
}

${ }^{\text {b }}$ Soil types and properties at the GPS coordinates provided, according to the National Cooperative Soil Survey, available through the web soil survey tool, and operated by the United States Department of Agriculture, Natural Resources Conservation Service.

${ }^{c}$ Organic matter. 
Kendall correlation coefficients were calculated using the PROC CORR procedure and by specifying the Kendall option for nonparametric analyses. Correlations were evaluated at the $\alpha=0.05$ significance level. Simple linear regression models, using PROC REG, were fitted to the relationship between apothecia and ascospore counts.

Weather and agronomic variable selection. Numerical gridded weather data, at a 5-km resolution, were obtained through cooperation with the Integrated Pest Information Platform for Extension and Education (iPiPE) project (Isard et al. 2015). This platform uses high-resolution real-time mesoscale analysis (RTMA) data (Benjamin et al. 2007), supplied by the information technology company ZedX, Inc. (Bellefonte, PA); data were sourced from the National Oceanic and Atmospheric Administration National Centers for Environmental Prediction. Site-specific weather data were generated for each trial year and location using coordinates obtained from a global positioning system (Table 1). Hourly estimates of air temperature, RH, dew point, wind speed, leaf wetness, and rainfall were obtained for each location. Two additional variables were created from the raw data to describe (i) the duration of time (hours) for which RH was $\geq 86 \%$ (RH86) and (ii) the duration of time (hours) for which air temperature was $\geq 10^{\circ} \mathrm{C}$ and $\leq 25^{\circ} \mathrm{C}$ (ATD). The ATD thresholds were established based on the germination data provided by Clarkson et al. (2007). From the RH range in Clarkson et al. (2014), on-site leaf wetness durations were used to determine the locally adjusted RH threshold (data not shown) (Rowlandson et al. 2015).

Daily mean, minimum, maximum, and sum values of all variables were generated in SAS using the UNIVARIATE procedure. From the resulting daily predictor values, 30-, 40-, 50-, and 60-day moving averages (mean, minimum, and maximum data) or sums (sum data) were generated by day and treatment $(n=444)$ (Clarkson et al. 2007). Moving averages or sums were calculated using the EXPAND procedure with MOVAVE or MOVSUM transformation options of 30, 40, 50 , and 60. All moving average and moving sum variables were used as potential independent variables in the model-building process.

Additionally, binary prediction variables were created for row, fungicide, and irrigation data and tested in the model. If data were collected in a plot with 0.36 - or $0.38-\mathrm{m}$ row spacing, then row was equal to 0 ; if collected in a plot with $0.76-\mathrm{m}$ row spacing, then row was equal to 1 . The fungicide variable was equal to 1 if any fungicide was applied in a plot or equal to 0 if no fungicide was applied. The irrigation variable was equal to 0 if plots were not overhead irrigated and to 1 if any overhead irrigation was used to supplement natural rainfall.

All gridded predictor variables for each moving-average duration and binary descriptors were used in Kendall correlation analyses with raw apothecial means using the PROC CORR procedure. Correlations were evaluated at the $\alpha=0.05$ significance level. The best moving average duration was selected based on number and strength of predictor variables, which were significantly correlated with mean apothecial counts. The selected moving average duration variables were used as independent variables in all modeling steps.

Subsequently, apothecial binary variables, defined based on thresholds of daily apothecial means, were used as potential response variables for the selected moving average predictors. Nine thresholds were defined: $0.1,0.2,0.3,0.4,0.5,0.6,0.7,0.8$, and 0.9 apothecia/ plot. For example, for the 0.1 threshold, 0 was assigned when the mean apothecia per plot was $<0.1$ and 1 if the mean was $\geq 0.1$. The best threshold was defined using the Kendall correlation analyses described previously and was used further as the dependent binary variable in the analysis.

On-site validation of gridded RTMA weather data. In Wisconsin in 2015 and 2016, on-site weather was monitored using a variety of sensors connected to a measurement datalogger for automatic data-acquisition (model CR1000; Campbell Scientific). Air temperature and RH (Vaisala T/RH probe, model HMP155A; Campbell Scientific) were measured at $3 \mathrm{~m}$ above the soil to remain at least $2 \mathrm{~m}$ above the soybean canopy throughout the season. Rainfall (Texas Electronics Tipping Bucket Gauge, model TE 525WS; Campbell Scientific) was monitored $1 \mathrm{~m}$ above the ground, with the bucket positioned on the south side of the mounting post. Leaf wetness was measured above and below the canopy using two dielectric sensors (Decagon Devices, model LWS-L; Campbell Scientific) positioned at a $45^{\circ}$ angle, facing north, and at heights of $0.9 \mathrm{~m}$ and $5 \mathrm{~cm}$ above the soil, respectively. The below-canopy sensor was placed in a soybean row to better mimic leaf wetness within the lower canopy. Soil moisture was also monitored using a volumetric water content reflectometer probe (model CS655; Campbell Scientific) buried $10 \mathrm{~cm}$ below the soil surface and inserted horizontally into the soybean root zone. In 2016, a wind sentry sensor anemometer and vane (R. M. Young Wind Sentry, model 3002; Campbell Scientific) was added to monitor wind speed and direction. The sentry was positioned $2.4 \mathrm{~m}$ above the soil surface and calibrated $2.73 \pm 0.6^{\circ}$ to true north.

All sensors were connected to the datalogger, which was attached to a 10-ft tripod (model CM106B; Campbell Scientific) constructed in border rows surrounding intensively monitored trials in West Madison and Arlington, WI (Table 1), where apothecia and ascospore presence was monitored. Measurements were taken every $5 \mathrm{~min}$ and averaged to calculate hourly surface and near-surface conditions. All sensors located in the soybean field trial were positioned within or above the soybean canopy and situated less than $25 \mathrm{~m}$ from the tripod station. In 2015, data were collected between 10 June and 7 October, or 28 to 147 DAS. In 2016, data were collected between 10 June and 10 October, which was 23 to 145 DAS. In both years, weather data collection began prior to first detection of apothecia and continued from approximately the V1 (first trifoliate) to the R8 (full maturity) growth stage.

Campbell Scientific weather station data were not used during model development. However, data were used to validate the accuracy of sitespecific gridded RTMA data. Station data for air temperature, $\mathrm{RH}$, rainfall, leaf wetness (using the above canopy sensor), and wind speed (in 2016) were used with gridded weather data in correlations analyses in SAS. Bias coefficients were calculated from the mean difference (generated using PROC MEANS) between hourly on-site Campbell weather station data and gridded RTMA data; bias coefficient $=$ hourly on-site data - hourly gridded data (Charney et al. 2013). Pearson correlation and Lin's concordance agreement analyses (Lin 1989) were also conducted using SAS code available through the Pennsylvania State University, Eberly College of Science (Lengerich 2017).

Logistic regression model development. In model development, weather variables of the selected moving average duration were used as independent variables, and the binary apothecial variable from the selected threshold for apothecia presence was used as the dependent variable. A mixed model using PROC GLIMMIX in SAS was used to evaluate the effects of fungicide, row, irrigation, and their interactions on apothecial presence. Additionally, all variables were included in Kendall correlation analyses using PROC CORR with the Kendall option; correlations were used to measure the degree of association between apothecial presence and biologically significant moisture and temperature variables.

Due to unexpectedly weak relationships between apothecial presence and temperature variables, Kendall correlations were reevaluated by the binary irrigation variable ( 0 or 1 ). Subsequently, models were fitted separately for irrigated and nonirrigated data. Correlations were evaluated at the $\alpha=0.05$ significance level and significant variables with correlation coefficients typically $>10.2 \mid$ were considered in logistic regression unless a variable was determined to be biologically important.

Logistic regressions were performed using the PROC LOGISTIC procedure with the descending option (to predict apothecia $=1$ ). All possible predictor variables were included in initial analyses using stepwise, forward, backward, and score selection methods. Variables with odds ratio point estimates of $>999.999$ or $<0.001$ were typically removed from subsequent analyses. Akaike's information criterion, percent concordant observations, and the area under the receiver operating characteristic (ROC) curve (c statistic) were used to evaluate models of interest.

Models containing commonly selected biologically significant variables across model selection methods were evaluated for goodness of fit using the Hosmer-Lemeshow test in an additional LACKFIT analysis in PROC LOGISTIC (Allison 1999; Hosmer and Lemeshow 2000). The max-rescaled $R^{2}$ statistic (Allison 1999) was also considered in model selection. The classification table (Hosmer and Lemeshow 2000), using the CTABLE option, was also used to (i) determine an 
appropriate apothecial probability action threshold (probability at which sensitivity and specificity converged) and (ii) evaluate potential models for percentages of correctness, sensitivity, specificity, false positives, and false negatives at the selected threshold.

Final models were evaluated for collinearity using a weighted regression procedure (Allison 1999) in PROC REG. Tolerance and variation inflation factors (VIF) were evaluated to assess collinearity between variables using the TOL and VIF options, respectively. Collinear variables were determined at tolerance values $<0.40$ and VIF values $>$ 3.0. Final model selection considered all described model selection criteria to assess explanatory power, as well as model parsimony, to obtain the simplest set of model parameters.

Model validation datasets. Model validations were conducted using four datasets from Michigan and Wisconsin, which were not used to develop the model. In Wisconsin in 2014, additional apothecial observations were collected from an irrigated breeding germplasm SSR nursery located at the West Madison Agricultural Research Station ( $n=525$ plot-level observations). The trial consisted of five replicates of 35 soybean lines or cultivars (total of 175 small plots) planted on a $0.76-\mathrm{m}$ row spacing. Observations were collected on 3 days, at the R3, R4, and R5 growth stages, in three squares $(0.76$ by $0.76 \mathrm{~m}$ each) per plot (total area of $1.73 \mathrm{~m}^{2}$ ). In 2016, additional observations were collected from an irrigated germplasm nursery at the Hancock Agricultural Research Station ( $n=168$ plot-level observations) and in a small, nonirrigated validation trial at the Arlington Agricultural Research Station ( $n=400$ plot-level observations). The irrigated trial contained six replicates of 14 lines or cultivars (total of 84 small plots) planted on a $0.76-\mathrm{m}$ row spacing. Observations were collected on 2 days, at the R2 and R4/5 growth stages, using the same method as described previously. In the nonirrigated Arlington validation trial, five treatments were replicated five times (total of 25 small plots) and planted on a $0.76-\mathrm{m}$ row spacing. Observations were collected on 16 days using the previously described method. DI observations were also collected near the end of the season, between R4 and R6. The number of diseased plants in the center two rows were counted and divided by the total number of plants in the stand to obtain DI (percentage); mean DI was calculated for each location. All three of the described trials were located either adjacent to, within the same fields, or within $2 \mathrm{~km}$ of the epidemiology trials where model building data were collected. Therefore, weather data used in validations were taken from previously described data sets.

In Michigan in 2015, additional observations were obtained from an on-farm trial located in Ionia, MI ( $n=9$ daily observations). These observations were collected in the same location as the 2016 apothecia observations which were included for model building. In 2015, however, only apothecial presence (1) or absence (0) was noted on 9 days between the R3 and R6 growth stages. No disease measurements were collected at this location; however, absence or presence of disease was noted. Including this dataset, 1,102 plot observations were made and 30 observation-days were considered in model validations. In irrigated trials, five daily observations were collected. In nonirrigated trials, 25 daily observations were used in validations.

Daily mean apothecial observations were compared with the predicted probabilities to evaluate model accuracy. If the daily model probability correctly predicted the presence of apothecia (at the established action threshold) above or below the disease control threshold of 3 to 4 apothecia per $9.75 \mathrm{~m}^{2}$ (Pan et al. 2001), or a mean of 0.5 to 0.7 apothecia in the total $1.73-\mathrm{m}^{2}$ area scouted per plot, then the observation was determined a success (1); if incorrectly predicted (e.g., observed a mean of $>0.5$ apothecia/plot and model prediction was less than the established action threshold), then the observation was determined a failure (0). The total number of successes observed out of the total number of observations was used to calculate the percentage of correct observations.

\section{Results}

Correlation analyses. Using the daily mean counts $(n=50)$, mean ascospore counts were strongly and positively associated with mean apothecial counts $(r=0.65, P<0.0001)$ (Supplementary Fig. S1). Daily mean ascospore counts were found to increase by 24 for each additional mean apothecia observed. Three daily mean observations were found to be influential and were removed based on residuals greater than five standard deviations from the mean and Cook's distance values of greater than 0.6 .

On-site validation of gridded weather data. Gridded weather data, derived for trial site based on site-specific GPS coordinates, were in agreement with on-site weather station data; however, the level of agreement varied according to the weather variable (Table 2). Bias coefficients indicated that gridded weather data typically overestimated average hourly on-site weather variables, except for $\mathrm{RH}$, which was underestimated. However, differences between gridded and on-site hourly averages were typically small (bias coefficients of -0.005 to -0.752 ); RH was estimated to differ by $3.6 \%$. Gridded air temperature and $\mathrm{RH}$ data were in higher agreement with on-site data-concordance correlation coefficients (ccc) $>0.90$, compared with rainfall and wind speed-ccc $>0.70$. The poorest agreement was found between estimated and on-site leaf wetness data-ccc $=0.47$.

Selection of response variables. Moving average durations were evaluated for number and strength of predictor variables $(n=34)$ significantly correlated with apothecial means (Table 3 ). Apothecial means were determined to be most correlated with 30-day moving averages, with 24 of 34 predictors $(73 \%)$ having significant $(P<0.05)$ correlations. Additionally, of the significantly correlated variables, 18 of 34 (55\%) had correlation coefficients $>10.10 \mid$. Therefore, 30-day moving average durations were used in all subsequent analyses as potential independent variables.

Various apothecial mean thresholds used to generate a binary apothecial response variable, were evaluated in correlation analyses with the previously selected 30-day moving average predictor variables $(n=$ 34) (Table 4). The chosen 30-day parameters were found to best describe the binary apothecial observations generated from a mean threshold of 0.3 . The resulting apothecial binary variable was significantly $(P<0.05)$ correlated with 23 of 34 predictor variables $(68 \%)$. Furthermore, $50 \%$ of the correlated variables resulted in Kendall coefficients $>$ 10.10l. The apothecial binary variable based on the 0.3 mean threshold best described the mean apothecial counts observed and was used in all subsequent analyses as the dependent variable.

Correlations between predictors and responses. Among the agronomic variables, only row spacing was determined to be a significant predictor $(P<0.0001)$. Therefore, row was included as a class variable

Table 2. Bias, Pearson, and concordance coefficients with corresponding standard deviations (SD) or 95\% confidence intervals (CI) for correlation analyses of gridded real-time mesoscale analysis (RTMA) data and on-site Campbell Scientific weather station data

\begin{tabular}{|c|c|c|c|c|c|}
\hline \multirow[b]{2}{*}{ Weather variable } & \multirow{2}{*}{$\frac{\text { Bias }^{\mathrm{a}}}{\text { Coefficient } \pm \text { SD }}$} & \multicolumn{2}{|c|}{ Pearson correlation } & \multicolumn{2}{|c|}{ Concordance correlation } \\
\hline & & Coefficient, $r$ & $95 \% \mathrm{CI}$ & Coefficient, $r_{c}$ & $95 \% \mathrm{CI}$ \\
\hline Air temperature & $-0.752 \pm 0.691$ & 0.99 & $(0.990,0.991)$ & 0.98 & $(0.978,0.979)$ \\
\hline Relative humidity & $3.658 \pm 4.715$ & 0.96 & $(0.956,0.961)$ & 0.93 & $(0.924,0.931)$ \\
\hline Rainfall & $-0.035 \pm 0.738$ & 0.83 & $(0.820,0.838)$ & 0.83 & $(0.817,0.836)$ \\
\hline Leaf wetness ${ }^{b}$ & $-0.005 \pm 0.510^{\mathrm{b}}$ & 0.47 & $(0.444,0.489)$ & 0.47 & $(0.444,0.489)$ \\
\hline Wind speed & $-0.735 \pm 0.845$ & 0.84 & $(0.832,0.854)$ & 0.74 & $(0.722,0.752)$ \\
\hline
\end{tabular}

${ }^{\text {a }}$ Bias coefficients were calculated from the mean difference between hourly on-site Campbell weather station data and gridded RTMA data; bias coefficient $=$ on-site data - gridded data.

${ }^{\mathrm{b}}$ Leaf wetness data were collected as binary data, and recorded as 1 if wetness was observed during the hour or 0 if no wetness was observed. A bias coefficient close to 0 would indicate good agreement between observed and gridded leaf wetness data. 
during model development. In preliminary analyses, Kendall correlations determined the apothecial presence to be negatively correlated with row width $(r=-0.25, P<0.0001)$ and fungicide application $(r=-0.10, P=0.03)$ and positively correlated with irrigation $(r=$ $0.15, P=0.0009)$. These were all expected effects of these predictors.

Additionally, Kendall correlations were used to identify gridded weather variables of interest for use in model development. As expected, apothecial presence was positively correlated with moisture variables such as the 30-day moving averages of daily mean $\mathrm{RH}$ $(r=0.12, P=0.0016)$ and leaf wetness $(r=0.17, P<0.0001)$. Also, apothecial presence was found to be negatively correlated with the 30-day moving average of daily mean wind speed $(r=-0.14, P=$ $0.0008)$, interpreted here as a measure of "dryness". The 30-day moving average of daily mean temperature, however, was only found to be very weakly correlated (negatively) to apothecial presence ( $r=$ $-0.08, P=0.05$ ). The weak correlations observed (coefficients $<1$ $0.2 \mathrm{l}$ ) and the unexpectedly weak effect of temperature (a biologically significant variable) on apothecial presence prompted separate analysis of data obtained from irrigated and nonirrigated sites.

When data from irrigated and nonirrigated sites were analyzed separately, the variables of interest had stronger and more significant correlations, with coefficients generally $>|0.2|$ and $P<0.0001$. Strong differences in temperature effect between systems also became quite apparent (Table 5). For nonirrigated fields, apothecial presence was positively correlated with the 30-day moving averages of the daily mean air temperature duration between 10 and $25^{\circ} \mathrm{C}(r=$ $0.35, P<0.0001)$, mean leaf wetness $(r=0.22, P<0.0001)$, and mean RH $(r=0.18, P<0.0001)$. Negative correlations were observed for 30-day moving average variables of maximum air temperature (MaxAT; $r=-0.30, P<0.0001$ ) and maximum wind speed (MaxWS; $r=-0.27, P<0.0001$ ). The row variable was not applicable for predicting apothecial presence under no irrigation because data were mostly collected in fields with $0.76-\mathrm{m}$ row spacing.

For irrigated fields, apothecial presence was found to be highly correlated with row width $(r=-0.41, P<0.0001)$ and 30-day moving averages of daily mean air temperature $(r=0.31, P<0.0001)$, maximum dew point $(r=0.28, P<0.0001)$, MaxAT $(r=0.27, P<0.0001)$, and maximum leaf wetness (MaxLW; $r=0.26, P=0.0006$ ). In both irrigated and nonirrigated cases, mean dew point and air temperature were positively correlated $(r=0.60, P<0.0001)$; mean relative humidity and mean leaf wetness were also positively correlated $(r>0.70, P<0.0001)$. In addition, mean air temperature duration between 10 and $25^{\circ} \mathrm{C}$ was negatively correlated with mean air temperature $(r>-0.60, P<$ $0.0001)$ and mean $\mathrm{RH} \geq 86 \%$ was positively correlated with mean $\mathrm{RH}(r \geq 0.70, P<0.0001)$.

Logistic regression model development and selection. Nonirrigated models tended to include $\mathrm{RH}$, air temperature, leaf wetness, and wind speed variables. Irrigated models tended to include row width, air temperature, leaf wetness, and dew point variables. Final model selection was conducted for combinations of one to four of these parameters, with preference given to variables with strong correlations to apothecial presence (Table 6). Duration variables of optimal air temperatures (between 10 and $25^{\circ} \mathrm{C}$ ) and $\mathrm{RH}(\geq 86 \%)$ were not used in final model selection due to atypical point estimates and 95\% Wald's confidence limits. The 30-day moving averages of daily minimums and 30-day moving sums averages of daily sums were also not included in final models because other variables were more explanatory and biologically relevant. Additionally, highly correlated variables were not selected together as sole parameters in final models (data not shown).

Table 3. Number of significant predictor variables $(n=33$ total) for each moving average duration correlated with apothecial means

\begin{tabular}{lcccc}
\hline & \multicolumn{4}{c}{ Number of correlated variables } \\
\cline { 2 - 5 } Criteria & 30-day & 40-day & 50-day & 60-day \\
\hline$P<0.05^{\text {a }}$ & 24 & 22 & 20 & 23 \\
Coefficient $>10.11$ & 18 & 16 & 15 & 13 \\
\hline
\end{tabular}

${ }^{\text {a }}$ Significance was determined at $\alpha=0.05$.
Models were assessed using the predicted model accuracy (percent correct), sensitivity, and specificity, as well as the tendency toward false positives and negatives. These percentages were determined from the PROC LOGISTIC classification table at the probability level of 0.40 . Model sensitivity and specificity tended to converge at a probability between 0.45 and 0.47 but the lower 0.40 threshold was selected to reduce the percentages of predicted false-negative errors. The 0.40 probability level was selected as a potential action threshold for model validation. Using this threshold, sites with model probabilities $\geq 0.40$ would be predicted to have an elevated risk of detecting apothecia in fields with a history of SSR.

For nonirrigated fields, one of the most parsimonious, best-fitting models used the 30-day moving averages of daily MaxAT and MaxWS to predict the probability of apothecial presence (equation 1). The models containing only the 30 -day moving average of daily MaxAT (equation 2) or the 30-day moving averages of daily MaxAT, maximum RH (MaxRH), and MaxWS (equation 3) were also models of interest.

$$
\begin{aligned}
\operatorname{Logit}(\mu)= & -0.47\left(\operatorname{MaxAT}_{30 M A}\right)-1.01\left(\operatorname{MaxWS}_{30 M A}\right) \\
& +16.65 \\
\operatorname{Logit}(\mu)= & -0.68\left(\operatorname{MaxAT}_{30 M A}\right)+17.19 \\
\operatorname{Logit}(\mu)= & -0.56\left(\operatorname{MaxAT}_{30 M A}\right)+0.10\left(\operatorname{MaxRH}_{30 M A}\right) \\
& -0.75\left(\operatorname{MaxWS}_{30 M A}\right)+8.20
\end{aligned}
$$

These models possessed c statistics between 0.7 and 0.8 , indicating acceptable discrimination (Hosmer and Lemeshow 2000), greater than $62 \%$ model accuracy, greater than $67 \%$ sensitivity, and greater than $57 \%$ specificity. The Hosmer-Lemeshow test, however, indicated a weak fit for all models presented $(P<0.05)$. The twovariable model had a relatively high c statistic (0.74), max-rescaled $R^{2}(0.2)$, and overall predicted model accuracy $(65.7 \%)$. This model also correctly predicted both epidemics $(72.5 \%)$ and nonepidemics $(62.0 \%)$. Thus, the two-variable model (equation 1) was selected for further model validations based on parsimony and fit. In this case, fit was defined as models that satisfied the majority of test statistics, forming a consensus, rather than passing a single test.

For irrigated fields, the model containing a row width variable and 30-day moving averages of MaxAT and MaxRH was one of the most parsimonious and best-fitting models (equation 4). Other models of interest were those containing a row width variable and the 30-day moving averages of MaxAT and MaxLW (equation 5), or containing a row width variable and only the 30-day moving average of MaxAT (equation 6). The row width variable was equal to 0 or 1 when the row spacing was 0.38 or $0.76 \mathrm{~m}$, respectively.

$$
\begin{aligned}
\operatorname{Logit}(\mu)= & -2.38(\text { Row })+0.65\left(\operatorname{MaxAT}_{30 M A}\right) \\
& +0.38\left(\text { MaxRH }_{30 M A}\right)-52.65 \\
\operatorname{Logit}(\mu)= & -2.39(\text { Row })+0.57\left(\operatorname{MaxAT}_{30 M A}\right) \\
& +7.95\left(\text { MaxLW }_{30 M A}\right)-20.67 \\
\operatorname{Logit}(\mu)= & -2.34(\text { Row })+0.69\left(\operatorname{MaxAT}_{30 M A}\right) \\
& -16.82
\end{aligned}
$$

Table 4. Number of significant 30-day moving average variables $(n=33$ total) correlated with apothecial binary response variables established at various thresholds

\begin{tabular}{lcccccccccc}
\hline & \multicolumn{1}{c}{$\begin{array}{c}\text { Number of correlated predictor variables for each } \\
\text { apothecial binary }\end{array}$} \\
\cline { 2 - 11 } & \multicolumn{1}{c}{ threshold } \\
Criteria & $\mathbf{0 . 1}$ & $\mathbf{0 . 2}$ & $\mathbf{0 . 3}$ & $\mathbf{0 . 4}$ & $\mathbf{0 . 5}$ & $\mathbf{0 . 6}$ & $\mathbf{0 . 7}$ & $\mathbf{0 . 8}$ & $\mathbf{0 . 9}$ & $\mathbf{1 . 0}$ \\
\hline$P<0.05^{\mathrm{b}}$ & 21 & 18 & 23 & 18 & 19 & 15 & 17 & 14 & 17 & 17 \\
Coefficient $>10.1 \mid$ & 14 & 12 & 17 & 16 & 15 & 10 & 11 & 11 & 10 & 10 \\
\hline
\end{tabular}

${ }^{a}$ Binary apothecial observations were generated for each designated mean threshold.

${ }^{\mathrm{b}}$ Significance was determined at $\alpha=0.05$. 
These models possessed c statistics indicating excellent discrimination between 0.8 and 0.9 (Hosmer and Lemeshow 2000), $>0.35$ max-rescaled $R^{2}$ values, and $>73 \%$ predicted model accuracies. The Hosmer-Lemeshow test, however, indicated potentially weak model fits for all models presented $(P<0.05)$. Both of the threevariable models had c statistics of $0.85,>0.4$ max-rescaled $R^{2}$ values, and relatively high predicted model accuracies ( 73 to $75 \%$ ), sensitivities ( 81 to $84 \%$ ), and specificities $(64.5 \%)$. Based on strong accuracy of the weather variables selected, the model considering air temperature and $\mathrm{RH}$ along with row spacing was selected for further model validation analyses (equation 4).

Model evaluation. Four small datasets, 30 mean daily observations were used to validate the selected nonirrigated (equation 1) and irrigated (equation 4) models. For each validation site, the probability of apothecial presence was generated using the following calculation (equation 7) with the appropriate model logit equation:

$$
\text { Probability }=\left[e^{\operatorname{logit}(\mu)}\right] /\left[1+e^{\operatorname{logit}(\mu)}\right]
$$

Using probability thresholds of 40 and $30 \%$, the models successfully predicted the risk for 67 and $70 \%$ of the daily observations, respectively (Table 7). Furthermore, the models successfully predicted the risk in 82 and $91 \%$ of the daily observations between the R1 and R3 soybean growth stages at the respective 30 and $40 \%$ thresholds.

The model predictions during the R1 and R3 flowering growth stages were also able to explain the end of season DI observed at three of the four validation sites (Fig. 1). In 2016, the irrigated Hancock trial (Fig. 1A) was predicted to have elevated risk (probability of apothecial presence $>40 \%$ ) at the end of the R1 to R3 period. At this location, apothecia were confirmed during and after the flowering period and a mean DI of $23.94 \%$ was observed. Conversely, very low risk $(<10 \%)$ was predicted during flowering in the 2014 irrigated
West Madison trial (Fig. 1B) and very low apothecial counts and DI $(0.04 \%)$ were observed. In 2016 , very low levels of apothecia were observed in the nonirrigated Arlington trial (Fig. 1C); risk during the flowering period was not predicted to be above $30 \%$ at this location, and a mean observed DI of $0.00 \%$ verified the low predicted risk. In 2015, the nonirrigated trial in Ionia, MI (Fig. 1D) was predicted to have elevated risk ( $>40 \%$ ) from R1 to R3, apothecia were confirmed during this period, and disease was observed at this location (data not shown).

\section{Discussion}

Several models are presented here to accurately predict the risk of apothecial presence in irrigated and nonirrigated soybean fields using high-resolution gridded weather data. We have identified two of these models to be further evaluated to assist farmers with fungicide application decisions. To our knowledge, these are the first reported weather-driven apothecial risk-assessment models for use in SSR management of soybean. These models incorporate 30-day moving averages of MaxAT, MaxRH, or MaxWS to predict the presence of apothecia in soybean fields. Model testing confirmed that the models developed here accurately predicted apothecial presence during the flowering growth stages and explain the overall disease observed in all four locations.

The association between apothecial and ascospore counts found in our study agrees with previous studies in sunflower (McCartney and Lacey 1991). Apothecial observations were usually associated with overall disease intensity but this is not consistent across studies (Foster et al. 2011; Schwartz and Steadman 1978), likely due to the probable aggregated distribution of inoculum (Boland and Hall 1988a,b). In the north-central region, short corn-soybean rotations are common and distribution of inoculum likely becomes more uniform with each subsequent epidemic. These models, therefore, are most appropriate for

Table 5. Weather or agronomic parameters significantly correlated with the apothecial binary variable in irrigated (1) and nonirrigated (0) fields, generated using a mean threshold of 0.3 apothecia/treatment, with correlation coefficients typically $>|0.2|$

\begin{tabular}{|c|c|c|c|c|}
\hline Irrigation & Variable & Parameter description $^{\mathbf{a}}$ & $\mathbf{C C}^{\mathbf{b}}$ & $P$ value \\
\hline 0 & MA_MinATD & 30-day average of daily minimum $\mathrm{ATD}, \geq 10^{\circ} \mathrm{C}$ and $\leq 25^{\circ} \mathrm{C}$ & 0.35 & $<0.0001$ \\
\hline 0 & MA_MeanATD & 30 -day average of daily mean $\mathrm{ATD}, \geq 10^{\circ} \mathrm{C}$ and $\leq 25^{\circ} \mathrm{C}$ & 0.35 & $<0.0001$ \\
\hline 0 & MA_MaxAT & 30-day average of daily maximum AT & -0.30 & $<0.0001$ \\
\hline 0 & MS_SumATD & 30 -day sum of daily sum ATD, $\geq 10^{\circ} \mathrm{C}$ and $\leq 25^{\circ} \mathrm{C}$ & 0.29 & $<0.0001$ \\
\hline 0 & MS_SumAT & 30-day sum of daily sum AT & -0.28 & $<0.0001$ \\
\hline 0 & MA_MeanAT & 30-day average of daily mean AT & -0.28 & $<0.0001$ \\
\hline 0 & MA_MaxWS & 30-day average of daily maximum WS & -0.27 & $<0.0001$ \\
\hline 0 & MA_MinRH86 & 30-day average of daily minimum $\mathrm{RH} \geq 86^{\circ} \mathrm{C}$ & -0.26 & $<0.0001$ \\
\hline 0 & MA_MeanLW & 30-day average of daily mean LW & 0.22 & $<0.0001$ \\
\hline 0 & MA_MinRH & 30-day average of daily minimum $\mathrm{RH}$ & 0.22 & $<0.0001$ \\
\hline 0 & MA_MeanWS & 30-day average of daily mean WS & -0.19 & 0.0002 \\
\hline 0 & MA_MeanRH & 30-day average of daily mean $\mathrm{RH}$ & 0.18 & 0.0002 \\
\hline 0 & MA_MaxDP & 30-day average of daily maximum DP & -0.15 & 0.0027 \\
\hline 0 & MA_MaxRH & 30-day average of daily maximum RH & 0.13 & 0.0070 \\
\hline 1 & Row & Binary variable, $0=0.36$ - or $0.38-\mathrm{m}$ row spacing and $1=0.76-\mathrm{m}$ row spacing & -0.41 & $<0.0001$ \\
\hline 1 & MA_MinLW & 30-day average of daily minimum LW & -0.31 & $<0.0001$ \\
\hline 1 & MS_SumAT & 30-day sum of daily sum AT & 0.31 & $<0.0001$ \\
\hline 1 & MA_MeanAT & 30-day average of daily mean AT & 0.31 & $<0.0001$ \\
\hline 1 & MA_MinAT & 30-day average of daily minimum AT & 0.29 & $<0.0001$ \\
\hline 1 & MA_MaxDP & 30-day average of daily maximum DP & 0.28 & $<0.0001$ \\
\hline 1 & MA_MinATD & 30 -day average of daily minimum $\mathrm{ATD}, \geq 10^{\circ} \mathrm{C}$ and $\leq 25^{\circ} \mathrm{C}$ & -0.28 & 0.0001 \\
\hline 1 & MS_SumDP & 30-day sum of daily sum DP & 0.27 & $<0.0001$ \\
\hline 1 & MA_MaxAT & 30-day average of daily maximum AT & 0.27 & $<0.0001$ \\
\hline 1 & MA_MaxLW & 30-day average of daily maximum LW & 0.26 & 0.0006 \\
\hline 1 & MA_MinDP & 30-day average of daily minimum DP & 0.25 & 0.0002 \\
\hline 1 & MA_MaxRH86 & 30-day average of daily maximum $\mathrm{RH} \geq 86^{\circ} \mathrm{C}$ & 0.24 & 0.0021 \\
\hline 1 & MA_MeanATD & 30 -day average of daily mean $\mathrm{ATD}, \geq 10^{\circ} \mathrm{C}$ and $\leq 25^{\circ} \mathrm{C}$ & -0.23 & 0.0021 \\
\hline 1 & MS_SumATD & 30 -day sum of daily sum ATD, $\geq 10^{\circ} \mathrm{C}$ and $\leq 25^{\circ} \mathrm{C}$ & -0.21 & 0.0015 \\
\hline 1 & MA_MinRH86 & 30 -day average of daily minimum $\mathrm{RH} \geq 86^{\circ} \mathrm{C}$ & -0.21 & 0.0097 \\
\hline 1 & MA_MaxRH & 30-day average of daily maximum RH & 0.16 & 0.0180 \\
\hline
\end{tabular}

a Abbreviations: air temperature (AT), air temperature duration (ATD), dew point (DP), leaf wetness (LW), relative humidity (RH), relative humidity duration (RH86), and wind speed (WS).

b Correlation coefficient.

c Significance was determined at $\alpha=0.05$. 
use in soybean fields with a prior history of SSR epidemics. Nonetheless, apothecia were found to be useful to explain disease development during soybean flowering.

Gridded remote sensing data, whenever accurate, are the best choice for risk assessment at a field or farm resolution without the constraint of purchasing and maintaining on-site sensors for each location (Magarey et al. 2001). The accuracy of some of the gridded weather variables are a suitable surrogate for on-site weather data. Continuous variables such as temperature and $\mathrm{RH}$ are typically easier to simulate, as confirmed by the correlation results presented in Table 2. Discontinuous variables such as precipitation and leaf wetness are more difficult to simulate, again apparent through correlation analyses (Table 2). However, the minor biases or disagreements observed between on-site and gridded weather data did not affect the development of the models presented here because only gridded data were considered in model building and two robust models were identified. Gridded weather data circumvent both the costly implementation of on-site weather stations and the possibility of on-site sensor failure or miscalibration, which would impede accurate model predictions (Magarey and Isard 2017). Using high-resolution gridded data, especially taking advantage of advances in the field, will facilitate the integration of these models into widely accessible algorithms (e.g., through the iPiPE) (Isard et al. 2015) for dissemination and adoption into SSR management programs.

Logistic regression modeling was conducted separately for irrigated and nonirrigated fields to preserve biologically important relationships between apothecia, temperature, and moisture variables. The effect of air temperature on apothecial germination and disease development has been recently well documented in studies of
Sclerotinia disease on lettuce (Clarkson et al. 2004, 2007, 2014). Historically, it was well established that $S$. sclerotiorum apothecia may form at low temperatures (between 10 and $25^{\circ} \mathrm{C}$ ) (Abawi and Grogan 1975; Bedi 1962; Coley-Smith and Cooke 1971; Willetts and Wong 1980). These findings support the negative effects of daily MaxAT on apothecial presence in nonirrigated fields, which was observed here. In irrigated fields, however, air temperature was found to be positively correlated with apothecial presence. Irrigation is expected to alter the canopy environment, and studies have shown that irrigated bean canopies exhibit cooler temperatures and prolonged leaf wetness (Blad et al. 1978). Additionally, irrigation also influences canopy structure by promoting fuller canopies, which are also more favorable to apothecial production (Schwartz and Steadman 1978). In irrigated fields, therefore, apothecial presence is likely promoted by the cooler temperatures within fuller canopies even though air temperatures are steadily increasing throughout the growing season. Warmer air temperatures in this scenario are believed to represent cooler canopy temperatures, which are favorable for apothecial development.

Although soil moisture is readily recognized as important for apothecial production (Abawi and Grogan 1975; Clarkson et al. 2004, 2007; Foster et al. 2011; Morrall 1977; Sun and Yang 2000; Wu and Subbarao 2008), the effects of RH and wind speed (a potential measure of "dryness") on carpogenic germination are less well studied. However, the findings of this study confirm the results of previous research on peanut, carrot, and lettuce that reports the positive effects of RH on diseases caused by Sclerotinia spp. (Clarkson et al. 2014; Foster et al. 2011; Smith et al. 2007; Young et al. 2004). RH has also been shown to affect ascospore dispersal of $S$. sclerotiorum in canola canopies (Qandah and del Rio Mendoza 2012) and, recently, changes in RH

Table 6. Model selection parameters for final irrigated (1) or nonirrigated (0) models of interest, containing one to four predictors of 30-day moving average weather variables or an agronomic row spacing variable (row1) ${ }^{\mathrm{a}}$

\begin{tabular}{|c|c|c|c|c|c|c|c|c|c|c|}
\hline Variables $^{\mathbf{b}}$ & IR & Con $(\%)$ & AIC & c & $R^{2}$ & Corr $(\%)$ & Sens $(\%)$ & Spec $(\%)$ & FPos $(\%)$ & FNeg $(\%)$ \\
\hline MaxAT & $\mathbf{0}$ & 70.5 & 342.08 & 0.72 & 0.16 & 75.2 & 67.6 & 79.3 & 35.5 & 18.4 \\
\hline MaxAT, MaxWS & $\mathbf{0}$ & 73.6 & 334.45 & 0.74 & 0.19 & 65.7 & 72.5 & 62.0 & 48.6 & 19.7 \\
\hline MaxAT, MaxLW & 0 & 72.1 & 322.12 & 0.72 & 0.19 & 69.6 & 72.5 & 67.9 & 44.4 & 18.3 \\
\hline MaxAT, MaxRH, MaxWS & $\mathbf{0}$ & 75.4 & 336.72 & 0.76 & 0.20 & 62.6 & 72.5 & 57.1 & 51.6 & 21.1 \\
\hline MaxAT, MeanRH, MeanWS & 0 & 74.9 & 326.40 & 0.75 & 0.24 & 62.9 & 66.7 & 60.9 & 51.4 & 23.3 \\
\hline MaxAT, MaxRH, MaxLW & 0 & 74.2 & 320.19 & 0.75 & 0.26 & 67.1 & 59.8 & 71.2 & 46.5 & 23.8 \\
\hline MaxAT, MeanRH, MaxWS & 0 & 74.1 & 332.71 & 0.75 & 0.21 & 64.7 & 72.5 & 60.3 & 49.7 & 20.1 \\
\hline MaxAT, MeanRH, MaxLW & 0 & 73.2 & 323.18 & 0.74 & 0.25 & 70.3 & 72.5 & 69.0 & 43.5 & 18.1 \\
\hline MaxAT, MeanRH, MeanLW & 0 & 73.0 & 335.0 & 0.74 & 0.20 & 65.4 & 67.6 & 64.1 & 48.9 & 21.9 \\
\hline MeanAT, MeanRH, MeanWS & 0 & 70.0 & 339.83 & 0.70 & 0.18 & 61.9 & 52.9 & 66.8 & 53.0 & 28.1 \\
\hline MeanAT, MeanRH, MeanLW & 0 & 68.5 & 346.09 & 0.69 & 0.16 & 65.0 & 67.6 & 63.6 & 49.3 & 22.0 \\
\hline Row1, MeanAT & 1 & 83.9 & 165.78 & 0.85 & 0.42 & 75.9 & 85.4 & 65.8 & 27.1 & 19.4 \\
\hline Row1, MaxAT & 1 & 83.5 & 169.84 & 0.84 & 0.39 & 76.6 & 87.8 & 64.5 & 27.3 & 16.9 \\
\hline Row1, MaxAT, MaxLW & 1 & 84.8 & 165.18 & 0.85 & 0.43 & 74.7 & 84.1 & 64.5 & 28.1 & 21.0 \\
\hline Row1, MeanAT, MaxRH & 1 & 84.8 & 166.02 & 0.85 & 0.43 & 74.1 & 84.1 & 63.2 & 28.9 & 21.3 \\
\hline Row1, MeanRH, MeanDP & 1 & 84.6 & 164.80 & 0.85 & 0.43 & 73.4 & 82.9 & 63.2 & 29.2 & 22.6 \\
\hline Row1, MeanRH, MaxDP & 1 & 84.5 & 164.46 & 0.85 & 0.44 & 71.5 & 82.9 & 59.2 & 31.3 & 23.7 \\
\hline Row1, MaxAT, MaxRH & 1 & 84.3 & 166.60 & 0.85 & 0.42 & 73.4 & 81.7 & 64.5 & 28.7 & 23.4 \\
\hline Row1, MeanAT, MaxLW & 1 & 84.3 & 164.87 & 0.85 & 0.43 & 72.2 & 80.5 & 63.2 & 29.8 & 25.0 \\
\hline Row1, MeanAT, MeanLW & 1 & 83.9 & 167.73 & 0.84 & 0.42 & 75.3 & 84.1 & 65.8 & 27.4 & 20.6 \\
\hline Row1, MaxRH, MaxDP & 1 & 83.7 & 170.12 & 0.84 & 0.40 & 71.5 & 80.5 & 61.8 & 30.5 & 25.4 \\
\hline Row1, MaxRH, MeanDP & 1 & 82.7 & 172.64 & 0.83 & 0.39 & 70.3 & 79.3 & 60.5 & 31.6 & 27.0 \\
\hline Row1, MeanAT, MeanRH, MeanLW & 1 & 86.3 & 162.44 & 0.87 & 0.46 & 74.7 & 84.1 & 64.5 & 28.1 & 21.0 \\
\hline Row1, MaxAT, MeanRH, MeanLW & 1 & 86.1 & 163.98 & 0.86 & 0.45 & 76.6 & 87.8 & 64.5 & 27.3 & 16.9 \\
\hline Row1, MaxAT, MaxRH, MaxDP & 1 & 85.3 & 167.37 & 0.86 & 0.43 & 71.5 & 81.7 & 60.5 & 30.9 & 24.6 \\
\hline Row1, MaxAT, MaxRH, MaxLW & 1 & 84.9 & 167.14 & 0.85 & 0.43 & 74.7 & 84.1 & 64.5 & 28.1 & 21.0 \\
\hline Row1, MaxAT, MeanRH, MaxLW & 1 & 84.9 & 167.17 & 0.85 & 0.43 & 74.7 & 84.1 & 64.5 & 28.1 & 21.0 \\
\hline Row1, MeanAT, MeanRH, MaxDP & 1 & 84.9 & 166.32 & 0.85 & 0.44 & 74.1 & 86.6 & 60.5 & 29.7 & 19.3 \\
\hline Row1, MeanAT, MaxRH, MaxDP & 1 & 84.7 & 167.67 & 0.85 & 0.43 & 72.2 & 84.1 & 59.2 & 31.0 & 22.4 \\
\hline Row1, MaxAT, MeanRH, MaxDP & 1 & 84.7 & 166.45 & 0.85 & 0.44 & 70.3 & 82.9 & 56.6 & 32.7 & 24.6 \\
\hline Row1, MaxAT, MeanRH, MeanDP & 1 & 84.7 & 166.76 & 0.85 & 0.43 & 72.8 & 82.9 & 61.8 & 29.9 & 23.0 \\
\hline Row1, MeanAT, MeanRH, MeanDP & 1 & 84.6 & 162.62 & 0.85 & 0.46 & 72.8 & 80.5 & 64.5 & 29.0 & 24.6 \\
\hline
\end{tabular}

${ }^{a}$ Abbreviations: $\mathrm{IR}=$ irrigation, $\mathrm{Con}=$ concordant, $\mathrm{AIC}=$ Akaike's information criterion for intercept and covariates, $\mathrm{c}=\mathrm{c}$ statistic (area under the receiver operating characteristic curve), and $R^{2}=$ maximum rescaled $R^{2}$. Percent correct (Corr), sensitivity (Sens), specificity (Spec), false positives (FPos), and false negatives (FNeg) determined at a probability threshold of 0.40 .

${ }^{\mathrm{b}}$ Maximum (Max) and mean air temperature (AT), dew point (DP), leaf wetness (LW), relative humidity (RH), and wind speed (WS). Models of interest, indicated in bold, were determined to be some of the most parsimonious and best-fitting; model equations are included in the results section. 
have also been shown to affect Botrytis cinerea conidia and S. sclerotiorum ascospore release in seed alfalfa fields (Reich et al. 2017). The observed negative effect of wind speed on apothecial presence also verifies findings in grape and lettuce of wind speed affecting conidial sporulation and lettuce drop incidence (Thomas et al. 1988; Wu and Subbarao 2006). Furthermore, air temperature, RH, and wind speed are generally known to affect leaf surface moisture conditions, which often promote pathogen and disease development (Huber and Gillespie 1992; Magarey et al. 2005). Narrow row spacing was also confirmed to promote apothecial presence (De Souza Jaccoud-Filho et al. 2016; Grau and Radke 1984). Thus, the models presented here demonstrate the positive effects of high $\mathrm{RH}$, low wind speed, and narrow row spacing in irrigated fields on apothecial presence. These variables are likely representative of increased moisture in the canopy microclimate, which is favorable for apothecial development.

During model selection, most criteria indicate strong fit, discrimination, and accuracy of the selected irrigated and nonirrigated models. Goodness-of-fit was not supported by Hosmer-Lemeshow tests $(P<0.05)$; however, some evidence against the strength of this statistic was presented by Allison (1999). In this study, the consensus of statistical tests was evaluated for model fitness rather than using only a single test. The irrigated model statistics indicated a stronger fit and higher predictive power than the nonirrigated model; however, fewer daily mean apothecial observations were collected from irrigated fields $(n=158)$ than from nonirrigated fields $(n=286)$. Therefore, the larger (nonirrigated) dataset is expected to have more variability and would result in a more challenging model fit. Despite the challenging model fits attributable to inherent variability between sites and years, these models possess acceptable or excellent discrimination, as indicated by the area under the ROC ( $c=0.7$ to 0.9$)$ as well as promising predicted accuracies (66 to 75\%), sensitivities (73 to $84 \%$ ), and specificities (62 to $65 \%$ ).

Furthermore, both models performed successfully in model validations, with an 82 to $91 \%$ accuracy during the R1 to R3 flowering period, dependent on the established risk threshold. As a result, these models predicted periods of elevated risk during which fungicide applications could have been applied for targeted SSR control. At two validation sites where low disease was observed $(<0.04 \%$ DI), the models predicted no spray applications during R1 to R3, which would have resulted in a one- to two-spray savings compared with standard SSR management programs. At another validation site, where considerable disease was observed ( $24 \%$ DI), the model predicted elevated risk at the R3 growth stage, which would have indicated a single application of fungicide was appropriate at this location. In a standard

Table 7. Model validation results from two irrigated (1) and two nonirrigated (0) trials in Wisconsin (WI) and Michigan (MI) in 2014 to 2016 a

\begin{tabular}{|c|c|c|c|c|c|c|c|c|c|c|}
\hline \multirow[b]{2}{*}{ Year } & \multirow[b]{2}{*}{ State } & \multirow[b]{2}{*}{ Location } & \multirow[b]{2}{*}{ IR } & \multirow[b]{2}{*}{ Row (m) } & \multirow[b]{2}{*}{$\operatorname{Prob}(0-1)^{c}$} & \multirow[b]{2}{*}{ Obs $^{d}$} & \multirow[b]{2}{*}{ GS } & \multirow[b]{2}{*}{ DI $(\%)^{\mathrm{e}}$} & \multicolumn{2}{|c|}{ Success or failure ${ }^{b}$} \\
\hline & & & & & & & & & $\operatorname{Pr} 0.40$ & $\operatorname{Pr} 0.30$ \\
\hline 2015 & MI & Ionia & 0 & 0.38 & 0.57 & 1 & R3 & 1 & 1 & 1 \\
\hline 2015 & MI & Ionia & 0 & 0.38 & 0.45 & 1 & R3 & 1 & 1 & 1 \\
\hline 2015 & MI & Ionia & 0 & 0.38 & 0.48 & 1 & $\mathrm{R} 4$ & 1 & 1 & 1 \\
\hline 2015 & MI & Ionia & 0 & 0.38 & 0.41 & 1 & $\mathrm{R} 4$ & 1 & 1 & 1 \\
\hline 2015 & MI & Ionia & 0 & 0.38 & 0.32 & 1 & R5 & 1 & 0 & 1 \\
\hline 2015 & MI & Ionia & 0 & 0.38 & 0.14 & 1 & R5 & 1 & 0 & 0 \\
\hline 2015 & MI & Ionia & 0 & 0.38 & 0.15 & 1 & R5 & 1 & 0 & 0 \\
\hline 2015 & MI & Ionia & 0 & 0.38 & 0.13 & 1 & R5-R6 & 1 & 0 & 0 \\
\hline 2015 & MI & Ionia & 0 & 0.38 & 0.12 & 0 & R5-R6 & 1 & 1 & 1 \\
\hline 2016 & WI & Arlington & 0 & 0.76 & 0.19 & 0.00 & V5 & 0.00 & 1 & 1 \\
\hline 2016 & WI & Arlington & 0 & 0.76 & 0.19 & 0.00 & $\mathrm{~V} 5 / 6$ & 0.00 & 1 & 1 \\
\hline 2016 & WI & Arlington & 0 & 0.76 & 0.21 & 0.00 & V6 & 0.00 & 1 & 1 \\
\hline 2016 & WI & Arlington & 0 & 0.76 & 0.26 & 0.00 & $\mathrm{R} 1$ & 0.00 & 1 & 1 \\
\hline 2016 & WI & Arlington & 0 & 0.76 & 0.20 & 0.00 & $\mathrm{R} 1$ & 0.00 & 1 & 1 \\
\hline 2016 & WI & Arlington & 0 & 0.76 & 0.19 & 0.32 & $\mathrm{R} 2$ & 0.00 & 1 & 1 \\
\hline 2016 & WI & Arlington & 0 & 0.76 & 0.21 & 0.04 & $\mathrm{R} 2$ & 0.00 & 1 & 1 \\
\hline 2016 & WI & Arlington & 0 & 0.76 & 0.17 & 0.00 & R3 & 0.00 & 1 & 1 \\
\hline 2016 & WI & Arlington & 0 & 0.76 & 0.17 & 0.08 & R3 & 0.00 & 1 & 1 \\
\hline 2016 & WI & Arlington & 0 & 0.76 & 0.16 & 1.84 & $\mathrm{R} 3$ & 0.00 & 0 & 0 \\
\hline 2016 & WI & Arlington & 0 & 0.76 & 0.14 & 1.28 & $\mathrm{R} 4$ & 0.00 & 0 & 0 \\
\hline 2016 & WI & Arlington & 0 & 0.76 & 0.13 & 1.44 & R5 & 0.00 & 0 & 0 \\
\hline 2016 & WI & Arlington & 0 & 0.76 & 0.16 & 1.60 & R5 & 0.00 & 0 & 0 \\
\hline 2016 & WI & Arlington & 0 & 0.76 & 0.20 & 0.84 & R5 & 0.00 & 0 & 0 \\
\hline 2016 & WI & Arlington & 0 & 0.76 & 0.30 & 0.04 & R5 & 0.00 & 1 & 0 \\
\hline 2016 & WI & Arlington & 0 & 0.76 & 0.39 & 0.84 & R6 & 0.00 & 1 & 1 \\
\hline 2014 & WI & West Madison & 1 & 0.76 & 0.03 & 0.00 & R3 & 0.04 & 1 & 1 \\
\hline 2014 & WI & West Madison & 1 & 0.76 & 0.02 & 0.23 & $\mathrm{R} 4$ & 0.04 & 1 & 1 \\
\hline 2014 & WI & West Madison & 1 & 0.76 & 0.03 & 0.34 & $\mathrm{R} 5$ & 0.04 & 1 & 1 \\
\hline 2016 & WI & Hancock & 1 & 0.76 & 0.38 & 2.26 & $\mathrm{R} 2$ & 23.94 & 0 & 1 \\
\hline 2016 & WI & Hancock & 1 & 0.76 & 0.68 & 3.26 & $\mathrm{R} 4 / 5$ & 23.94 & 1 & 1 \\
\hline
\end{tabular}

a Model accuracy was determined using the daily model probabilities and corresponding daily apothecial observations. Abbreviations: IR $=$ irrigation, Row $=$ row spacing, and GS = growth stage.

${ }^{b}$ Model success or failure determined by comparing daily model probabilities, using either a 0.40 or 0.30 risk threshold (Pr 0.40 or Pr 0.30 , respectively), with corresponding daily apothecial observations. If model probabilities corresponded to the daily apothecial observations, then a success (1) was recorded; if model probabilities did not correspond to daily apothecial observations, then a failure $(0)$ was recorded. Percent correct $=67$ and $70 \%$ for Pr 0.40 and Pr 0.30 , respectively, and percent correct at R1 to R3 growth stages $=82$ and $91 \%$ for Pr 0.40 and Pr 0.30, respectively.

${ }^{c}$ Daily probability (Prob) of apothecial presence was calculated using the selected models for irrigated $[$ Logit $(\mu)=-2.38 \times$ Row $+0.65 \times$ MaxAT $+0.38 \times$ MaxRH -52.65 , where Row $=1$ if $0.76-\mathrm{m}$ row spacing or 0 if $0.38-\mathrm{m}$ row spacing, MaxAT = maximum air temperature, and MaxRH = maximum relative humidity] and nonirrigated [Logit $(\mu)=-0.47 \times$ MaxAT $-1.01 \times$ MaxWS +16.65 , where MaxWS $=$ maximum wind speed) fields; probability $=$ $\left[\mathrm{e}^{\operatorname{logit}(\mu)}\right] /\left[1+\mathrm{e}^{\operatorname{logit}(\mu)}\right]$.

${ }^{\mathrm{d}}$ Daily apothecial presence observed (presence $=1$ or absence $=0$ ). Apothecial means were evaluated for presence or absence at the mean disease control threshold of 0.5 to 0.7 apothecia observed per a $1.73-\mathrm{m}^{2}$ area, or the total area scouted per plot.

e Average end-of-season disease incidence (DI) (presence $=1$ or absence $=0$ ) was calculated from the total number of diseased plants in the two center rows of each plot divided by the total number of plants in the two center rows, as determined by stand counts, and multiplied by 100 to obtain a percentage. 
two-spray fungicide program, this would have reduced management to a single application and would have effectively timed the fungicide treatment to target a critical elevated-risk event for improved SSR management. Additional field studies are required to further confirm these results.

Foster et al. (2011) presented evidence for using architectural and phenological initiation parameters such as canopy closure in SSR prediction models for carrot systems. In soybean, SSR development is known to be dependent on canopy closure to promote a favorable environment for apothecial germination, as well as soybean flowering to provide a nutrient source for infectious ascospores (Boland and Hall 1988a; Grau and Hartman 2015; Peltier et al. 2012; Saharan and Mehta 2008; Schwartz and Steadman 1978). In soybean, we plan to integrate the models presented here into a risk assessment algorithm which also considers canopy closure and soybean flowering. This algorithm will be deployed as a mobile- or web-accessible tool for users to assist in making SSR management decisions. Ultimately, site-specific model probabilities would be generated and management recommendations would be contingent on soybean flowering (R1-R3) and canopy development using row closure thresholds (M. L. Fall, personal communication). These models are currently available to authorized extension personnel via iPiPE for development and evaluation of these algorithms.

The model is currently limited by the number and size of validation datasets, as well as the absence of a well-tested action threshold. In the future, however, additional multistate and year model validations will be conducted using versions of the described algorithm. Model performance will be evaluated in irrigated and nonirrigated soybean fields with intensive monitoring of apothecial presence and subsequent disease development. Furthermore, validations will be used to determine appropriate probability action thresholds for a variety of scenarios. Common fungicide programs and regional cultivar resistance are also important considerations in the development of the proposed risk assessment tool.

Overall, extensive apothecial observations from nine site-years and subsequent logistic regression analyses resulted in the identification of

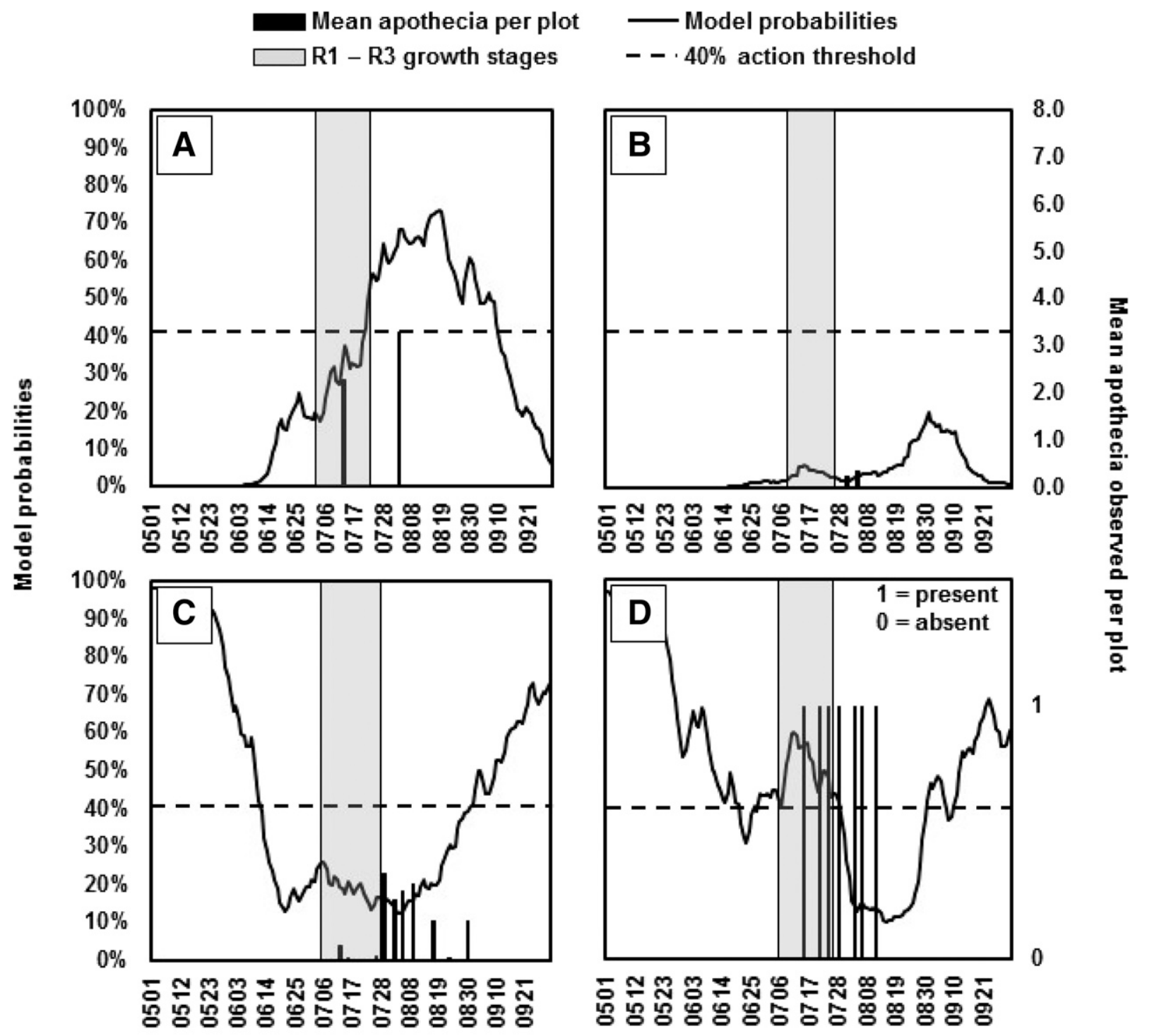

\section{Date (MMDD)}

Fig. 1. Model validations for irrigated trials in A, Hancock, WI in 2016 and B, West Madison, WI in 2014; and nonirrigated trials in C, Arlington, WI in 2016 and D, lonia, Ml in 2015. The solid line shows probabilities of apothecial presence which were calculated between 1 May and 1 October using the selected models for irrigated [Logit $(\mu)=-2.38 \times$ Row + $0.65 \times$ MaxAT $+0.38 \times \mathrm{MaxRH}-52.65$, where Row $=1$ if $0.76-\mathrm{m}$ row spacing or 0 if $0.38-\mathrm{m}$ row spacing, MaxAT = maximum air temperature, and MaxRH $=$ maximum relative humidity] and nonirrigated [Logit $(\mu)=-0.47 \times$ MaxAT $-1.01 \times$ MaxWS +16.65 , where MaxWS $=$ maximum wind speed) fields; probability $=\left[e^{\text {logit }(\mu)}\right] /\left[1+e^{\operatorname{logit}(\mu)}\right]$. Solid bars in $A, B$, and $C$ indicate daily apothecial means per plot, in a total scouted area of $1.73 \mathrm{~m}^{2}$; in $\mathrm{D}$, bars indicate apothecial presence (1) or absence (0). The gray box represents the $\mathrm{R} 1$ to R3 flowering period. The dotted line represents the preliminary action threshold of $40 \%$ probability. Sclerotinia stem rot (SSR) incidence of $0.04 \%$ was observed at location B and $0.00 \%$ at location C. At location A, 23.94\% incidence was observed; at location D, incidence data were not collected; however, SSR was present. 
novel models which accurately predict apothecial presence in irrigated and nonirrigated soybean fields using high-resolution gridded weather data. Validated models will be integrated into an algorithm considering soybean phenology and canopy architecture to provide risk assessment information for incorporation into integrated SSR management programs.

\section{Acknowledgments}

We thank our undergraduate research assistants T. Blackwell, D. Holtz, H. Lucas, M. Weber, and M. Young (in Wisconsin); J. Bunner, Z. Sundin, C. Meredith, and K. Naasko (in Michigan); and R. Kempker (in Iowa) for their contributions to the intensive field studies conducted in this work; C. Groves for her laboratory support; and the iPiPE personnel for their continued technical support in using modeled weather data in our apothecial prediction model. The iPiPE CAP is supported by the United States Department of Agriculture (USDA) National Institute of Food and Agriculture Agriculture and Food Research Initiative Competitive Grants Program Food Security Challenge Area Grant 2015-6800423179. We also thank the USDA Hatch program, the University of WisconsinMadison Science and Medicine Graduate Research Scholars fellowship program, the Wisconsin Soybean Marketing Board, the Michigan Soybean Promotion Council, the North Central Soybean Research Program, and the United Soybean Board for their generous support.

\section{Literature Cited}

Abawi, G. S., and Grogan, R. G. 1975. Source of primary inoculum and effects of temperature and moisture on infection of beans by Whetzelinia sclerotiorum. Phytopathology 65:300-309.

Allen, T. W., Bradley, C. A., Sisson, A. J., Byamukama, E., Chilvers, M. I., Coker, C. M., Collins, A. A., Damicone, J. P., Dorrance, A. E., Dufault, N. S., Esker, P. D., Faske, T. R., Giesler, L. J., Grybauskas, A. P., Hershman, D. E., Hollier, C. A., Isakeit, T., Jardine, D. J., Kemerait, R. C., Kleczewski, N. M., Koenning, S. R., Kurle, J. E., Malvick, D. K., Markell, S. G., Mehl, H. L., Mueller, D. S., Mueller, J. D., Mulrooney, R. P., Nelson, B. D., Newman, M. A., Osborne, L., Overstreet, C., Padgett, G. B., Phipps, P. M., Price, P. P., Sikora, E. J., Smith, D. L., Spurlock, T. N., Tande, C. A., Tenuta, A. U., Wise, K., Wrather, J. A., and Young-Kelly, H. 2017. Soybean yield loss estimates due to disease in the United States and Ontario, Canada, from 2010 to 2014. Plant Health Prog. 18:19-27.

Allison, P. D. 1999. Logistic Regression Using the SAS System: Theory and Application. SAS Institute Inc., Cary, NC.

Bedi, K. S. 1962. Temperature in relation to the formation of apothecia of Sclerotinia sclerotiorum (Lib.) de Bary. Proc. Indiana Acad. Sci. 55: 244-250.

Benjamin, S., Brown, J., and Manikin, G. 2007. The RTMA background-Hourly downscaling of RUC data to 5-km detail. Pages 1-4 in: 23rd Conf. IIPS.

Blad, B. L., Steadman, J. R., and Weiss, A. 1978. Canopy structure and irrigation influence white mold disease and microclimate of dry edible beans. Phytopathology 68:1431-1437.

Boland, G. J., and Hall, R. 1988a. Epidemiology of Sclerotinia stem rot of soybean in Ontario. Phytopathology 78:1241-1245.

Boland, G. J., and Hall, R. 1988b. Relationships between the spatial pattern and number of apothecia of Sclerotinia sclerotiorum and stem rot of soybean. Plant Pathol. 37:329-336.

Boland, G. J., and Hall, R. 1994. Index of plant hosts of Sclerotinia sclerotiorum. Can. J. Plant Pathol. 16:93-108.

Bradley, C. A., Allen, T., and Esker, P. D. 2016. Estimates of soybean yield reductions caused by diseases in the United States. Online publication. Univ. Ill. Coll. Agric. Consumer Environ. Sci. Dep. Crop Sci. Ext. Outreach. http:// extension.cropsciences.illinois.edu/fieldcrops/diseases/yield_reductions.php

Charney, J. J., Service, U. F., and Kiefer, M. T. 2013. An investigation of the differences between Real Time Mesoscale Analysis and observed meteorological conditions at RAWS stations in the northeast United States. JFSP Res. Proj. Rep.

Clarkson, J. P., Fawcett, L., Anthony, S. G., and Young, C. 2014. A model for Sclerotinia sclerotiorum infection and disease development in lettuce, based on the effects of temperature, relative humidity and ascospore density. PLoS One 9:e94049.

Clarkson, J. P., Phelps, K., Whipps, J. M., Young, C. S., Smith, J. A., and Watling, M. 2004. Forecasting Sclerotinia disease on lettuce: Toward developing a prediction model for carpogenic germination of sclerotia. Phytopathology 94: 268-279.

Clarkson, J. P., Phelps, K., Whipps, J. M., Young, C. S., Smith, J. A., and Watling, M. 2007. Forecasting Sclerotinia disease on lettuce: A predictive model for carpogenic germination of Sclerotinia sclerotiorum sclerotia. Phytopathology 97:621-631.

Coley-Smith, J., and Cooke, R. 1971. Survival and germination of fungal sclerotia. Annu. Rev. Phytopathol. 9:65-92.

de Souza Jaccoud-Filho, D., Sartori, F. F., Manosso-Neto, M., Vrisman, C. M., da Cunha Pierre, M. L., Berger-Neto, A., Túllio, H. E., Justino, A., Ferreira da Fonseca, A., and Zanon, S. 2016. Influence of row spacing and plant population density on management of "white mould" in soybean in southern Brazil. Aust. J. Crop Sci. 10: $161-168$.
Fehr, W. R., Caviness, C. E., Burmood, D. T., and Pennington, J. S. 1971. Stage of development descriptions for soybeans, Glycine $\max$ (L.) Merill. Crop Sci. 11: 929-931.

Foster, A. J., Kora, C., McDonald, M. R., and Boland, G. J. 2011. Development and validation of a disease forecast model for Sclerotinia rot of carrot. Can. J. Plant Pathol. 33:187-201.

Grau, C., and Radke, V. 1984. Effects of cultivar and cultural practices on Sclerotinia stem rot of soybean. Plant Dis. 68:56-58.

Grau, C., Radke, V., and Gillespie, F. 1982. Resistance of soybean cultivars to Sclerotinia sclerotiorum. Plant Dis. 66:506-508.

Grau, C. R., and Hartman, G. L. 2015. Compendium of Soybean Diseases, 5th ed. G. L. Hartman, J. C. Rupe, E. J. Sikora, L. L. Domier, J. A. Davis, and K. L. Steffey, eds. The American Phytopathological Society, St Paul, MN.

Harikrishnan, R., and del Río, L. E. 2008. A logistic regression model for predicting risk of white mold incidence on dry bean in North Dakota. Plant Dis. 92:42-46.

Hosmer, D. W., and Lemeshow, S. 2000. Applied Logistic Regression, second ed. John Wiley and Sons, Hoboken, NJ.

Huber, L., and Gillespie, T. J. 1992. Modeling leaf wetness in relation to plant disease epidemiology. Annu. Rev. Phytopathol. 30:553-577.

Isard, S. A., Russo, J. M., Magarey, R. D., Golod, J., and Vankirk, J. R. 2015 Integrated pest information platform for extension and education (iPiPE): Progress through sharing. J. Integr. Pest Manage. 6:15.

Kohn, L. M. 1979. A monographic revision of the genus Sclerotinia. Mycotaxon 9:365-444.

Lehner, M. S., Pethybridge, S. J., Meyer, M. C., and Del Ponte, E. M. 2017 Meta-analytic modelling of the incidence-yield and incidence-sclerotial production relationships in soybean white mould epidemics. Plant Pathol. 66 460-468

Lengerich, R. 2017. Concordance correlation coefficient for measuring agreement. In: Statistics 509: Design and Analysis of Clinical Trials. Online publication. The Pennsylvania State University, Eberly College of Science. https://onlinecourses. science.psu.edu/stat509/sites/onlinecourses.science.psu.edu.stat509/files/ lesson18/19.2_agreement_concordanc.sas

Lin, L. I. 1989. A concordance correlation coefficient to evaluate reproducibility. Biometrics 45:255-268.

Magarey, R., Seem, R., Russo, J., Zack, J., Waight, K., Travis, J., and Oudemans, P. V. 2001. Site-specific weather information without on-site sensors. Plant Dis. 85:1216-1226

Magarey, R. D., and Isard, S. A. 2017. A troubleshooting guide for mechanistic plant pest forecast models. J. Integr. Pest Manage. 8:3.

Magarey, R. D., Seem, R. C., Weiss, A., Gillespie, T., and Huber, L. 2005 Estimating surface wetness on plants. Pages 199-226 in: Agron. Monogr. No. 47. American Society of Agronomy, Crop Science Society of America, Soil Science Society of America, Madison, WI.

McCartney, H. A., and Lacey, M. E. 1991. The relationship between the release of ascospores of Sclerotinia sclerotiorum, infection and disease in sunflower plots in the United Kingdom. Grana 30:486-492.

Mila, A. L., Carriquiry, A. L., and Yang, X. B. 2004. Logistic regression modeling of prevalence of soybean Sclerotinia stem rot in the north-central region of the United States. Phytopathology 94:102-110.

Morrall, R. A. A. 1977. A preliminary study of the influence of water potential on sclerotium germination in Sclerotinia sclerotiorum. Can. J. Bot. 55:8-11.

Mueller, D. S., Bradley, C. A., Grau, C. R., Gaska, J. M., Kurle, J. E., and Pedersen, W. L. 2004. Application of thiophanate-methyl at different hos growth stages for management of Sclerotinia stem rot in soybean. Crop Prot. 23:983-988.

Pan, H., Xi, J., Liu, W., Wan, Q., and Li, H. 2001. Optimal stage and threshold of the control of Sclerotinia rot. Acta Phytophylac. Sin. 28:299-302.

Peltier, A. J., Bradley, C. A., Chilvers, M. I., Malvick, D. K., Mueller, D. S., Wise, K. A., and Esker, P. D. 2012. Biology, yield loss and control of Sclerotinia stem rot of soybean. J. Integr. Pest Manage. 3:B1-B7.

Qandah, I. S., and del Rio Mendoza, L. E. 2012. Modelling inoculum dispersal and Sclerotinia stem rot gradients in canola fields. Can. J. Plant Pathol. 34 390-400.

Reich, J., Chatterton, S., and Johnson, D. 2017. Temporal dynamics of Botrytis cinerea and Sclerotinia sclerotiorum in seed alfalfa fields of Southern Alberta, Canada. Plant Dis. 101:331-343.

Rowlandson, T., Gleason, M., Sentelhas, P., Gillespie, T., Thomas, C., and Hornbuckle, B. 2015. Reconsidering leaf wetness duration determination for plant disease management. Plant Dis. 99:310-319.

Saharan, G. S., and Mehta, N. 2008. Sclerotinia Diseases of Crop Plants: Biology, Ecology and Disease Management. Springer Science \& Business Media B.V., Dordrecht, The Netherlands.

Schwartz, H. F., and Steadman, J. R. 1978. Factors affecting sclerotium populations of, and apothecium production by, Sclerotinia sclerotiorum. Phytopathology 68:383-388.

Smith, D. L., Hollowell, J. E., Isleib, T. G., and Shew, B. B. 2007. A site-specific, weather-based disease regression model for Sclerotinia blight of peanut. Plan Dis. 91:1436-1444

Steadman, J. R., Marcinkowska, J., and Rutledge, S. 1994. A semi-selective medium for isolation of Sclerotinia sclerotiorum. Can. J. Plant Pathol. 16 68-70. 
Sun, P., and Yang, X. B. 2000. Light, temperature, and moisture effects on apothecium production of Sclerotinia sclerotiorum. Plant Dis. 84:1287-1293.

Thomas, C., Marois, J., and English, J. 1988. Effects of wind speed, air temperature, and relative humidity on development of aerial mycelium and conidia of Botrytis cinerea on grape. Phytopathology 78:260-265.

Twengström, E., Sigvald, R., Svensson, C., and Yuen, J. 1998. Forecasting Sclerotinia stem rot in spring sown oilseed rape. Crop Prot. 17:405-411.

USDA-NASS. 2017. United States Soybean Prices. United States Department of Agriculture-National Agricultural Statistics Service, Washington, DC.

Wegulo, S. N., Sun, P., Martinson, C. A., and Yang, X. B. 2000. Spread of Sclerotinia stem rot of soybean from area and point sources of apothecial inoculum. Can. J. Plant Sci. 80:389-402.

Willetts, H. J., and Wong, J. A.-L. 1980. The biology of Sclerotinia sclerotionum, S. trifoliorum, and S. minor with emphasis on specific nomenclature. Bot. Rev. 46:101-165.
Wrather, A., Shannon, G., Balardin, R., Carregal, L., Escobar, R., Gupta, G., Ma, Z., Morel, W., Ploper, D., and Tenuta, A. 2010. Effect of diseases on soybean yield in the top eight producing countries in 2006. Online publication. Plant Heal. Prog. doi:10.1094/PHP-2010-0125-01-RS

Wu, B. M., and Subbarao, K. V. 2006. Analyses of lettuce drop incidence and population structure of Sclerotinia sclerotiorum and S. minor. Phytopathology 96:1322-1329.

Wu, B. M., and Subbarao, K. V. 2008. Effects of soil temperature, moisture, and burial depths on carpogenic germination of Sclerotinia sclerotiorum and S. minor. Phytopathology 98:1144-1152.

Young, C. S., Clarkson, J. P., Smith, J. a., Watling, M., Phelps, K., and Whipps, J. M. 2004. Environmental conditions influencing Sclerotinia sclerotiorum infection and disease development in lettuce. Plant Pathol. 53:387-397. 